\title{
The ballistic behaviour of explosively shattered alumina and silicon carbide targets
}

\author{
H. Nanda ${ }^{1,2}$,G.J. Appleby-Thomas ${ }^{1}$, DC Wood ${ }^{1}$ and P.J. Hazell*1 \\ ${ }^{1}$ Cranfield Defence and Security, Cranfield University, DA-CMT, Shrivenham, Swindon, \\ Wiltshire, SN6 8LA, UK. \\ ${ }^{2}$ Now at: Ordnance Factory Bhandara, Under Ministry of Defence, Government of India \\ Jawaharnagar, Bhandara - 441906 Maharashtra, INDIA \\ * Corresponding author
}

\begin{abstract}
The resistance offered by three ceramic materials of varying strength that have been subjected to explosive loading has been investigated by depth-of-penetration (DoP) testing. Each material was completely penetrated by a tungsten carbide-cored projectile and the residual penetration into a ductile aluminium alloy backing material was measured. The resulting ballistic performance of each damaged ceramic was found to be similar implying that the resistance offered to the projectile by the damaged ceramic is not dependent on the intrinsic strength properties of the intact material. This was taken as evidence that the important controlling parameter for enhancing the ballistic performance of a damaged ceramic material was not the strength of the ceramic but rather the fragment morphology.
\end{abstract}

Keywords: ballistic testing; hardness measurement; ceramics; failure; fracture

${ }^{1}$ Email: p.j.hazell@cranfield.ac.uk; Tel: +44 (0) 1793785731 


\section{INTRODUCTION}

Understanding the nature of the resistance to penetration by shattered brittle materials is important for two reasons. Firstly, the lack of a multi-hit ability with ceramic materials, when compared to metallic systems, often precludes them from being used in an environment where they would be subjected to very many impacts in a short space of time. After the first impact, it would be expected that the target would be heavily damaged by the bullet and therefore any subsequent projectile would penetrate through already-fractured material. An understanding of the ballistic performance of this fractured material is therefore important. Secondly, the strength of the shattered material and how it varies between different ceramics is an unknown quantity, and this is especially important for when computational models are formulated. In these cases, it is frequently necessary to calibrate the model to fit the experimental data by assuming strength-related constants e.g., [1]. Even with this, there is debate with regards to the magnitude of the strength of the damaged material and how it behaves under load [2-7].

A common way of assessing the ballistic behaviour of a ceramic is by using the depth-of-penetration technique e.g., [8-18]. Depth-of-penetration testing is achieved by firing at a target consisting of an armour tile attached to a ductile backing material and recording the resulting depth-of-penetration (DoP). The measured depth is then compared to a value of penetration depth achieved without the armour tile in place [19-20]. In this work, we have carried out such penetration tests into several materials that have been explosively shattered. The aim here is to look at how the resistance to penetration offered by a tile changed when it was 
heavily damaged. For the explosively shattered samples, we have chosen to limit the scope of the study to cases where the projectile core is not shattered or broken. The advantage of this approach is that no energy is consumed in doing work on the core and therefore the measured depth of penetration into a witness plate provides a metric for the mean resisting force offered by the tile [21-23].

\section{EXPERIMENTAL SET-UP}

\section{Materials used}

For the backing material used in these DoP experiments, a common engineering aluminium alloy $\mathrm{Al}$ 6082-T651 was chosen ( $\mathrm{Y}=240 \mathrm{MPa}$ ). The test backing-plates were $50 \times 50 \mathrm{~mm}$ pieces cut from a single $25 \mathrm{~mm}$ thick plate. For each ceramic tile of specific thickness $\left(t_{c}\right)$, a single bullet was fired at the target and the residual penetration $\left(p_{r}\right)$ into the aluminium alloy was measured for different confinement conditions (see Fig. 1); at least three experiments were conducted for each material. Finally, all targets were heavily confined around their radial edges to reduce the propensity of release waves to damage the target during penetration.

\section{Fig. 1 NEAR HERE}

Three brittle materials of varying strengths were tested in this study: Sintox $^{\mathrm{TM}}$ FA (alumina) manufactured by Morgan Matroc Ltd with thicknesses of 6.5 
mm, $12.0 \mathrm{~mm}, 12.7 \mathrm{~mm}$ and $20.0 \mathrm{~mm}$; a pressureless-sintered silicon carbide manufactured by Morgan AM\&T (Purebide ${ }^{\circledR}$ PS-5000) with a thickness of $9.0 \mathrm{~mm}$; and a liquid-phase sintered silicon carbide manufactured by ESK (Ekasic ${ }^{\circledR T}$ ) of thickness $10.2 \mathrm{~mm}$. All tiles were $50 \mathrm{~mm} \times 50 \mathrm{~mm}$ in areal size and were radially confined by high-strength steel platens during explosive loading and subsequent ballistic testing (see Fig. 1 (b) and (c)).

For completeness, the elastic properties of the materials were established ultrasonically using Panametrics’ 5MHz longitudinal and shear-wave probes with the pulse-echo method. The hardness values were calculated from a series of microhardness tests using an Indentec HWDM7. The properties of the materials used in this experimental programme are presented in Table 1. All of the ceramic materials were tested according to HV2.0.

\section{Table 1: NEAR HERE}

\section{Explosive loading}

A radial confinement rig was designed to accommodate the tile during explosive loading [6]. Prior to explosive shattering, each tile was glued to an aluminium alloy-backing plate using Araldite 2015. This was applied to the mating surfaces and then the material and aluminium plate were pushed together and twisted / oscillated with the aim of eliminating any potential interfacial air gaps or inclusions. The explosive loading of the tile was done with the objective of predamaging the tile in such a way that it would not transform into excessive debris but instead retained structure. 
The explosive loading was achieved by placing a circular mass of DEMEX 200 sheet explosive onto a 10-mm thick mild steel plate. The mild steel plate was then positioned on top of the target tile. Detonation of the explosive was achieved with a commercially available L2A1 electrical detonator. Fig. 2 shows the experimental setup for the explosive loading of the tile.

For the alumina, $6.0 \mathrm{~g} \pm 1.5 \mathrm{~g}$ of explosive was used while $2.5 \mathrm{~g} \pm 0.1 \mathrm{~g}$ of explosive was used for each of the silicon carbides as the PS-5000 grade possessed a relatively low fracture toughness [25]. For each explosive loading configuration a minimum of 6 samples were tested with at least 3 samples retained for ballistic testing and 3 samples processed for damage assessment.

Fig. 2: NEAR HERE

\section{Damage assessment}

After the tile was explosively loaded, the samples was recovered and processed for damage assessment. In all cases, despite the samples being damaged by the explosive loading process, they retained a degree of structural integrity and remained mostly intact. Consequently each sample was subsequently ground using the palm of the hand to encourage separation of discrete fragments along fracture surfaces. The resulting fragments were then sieved and weighed using 8 discrete mesh sizes ranging from $0.5 \mathrm{~mm}$ to $4.0 \mathrm{~mm}$. This was a similar range of sizes to that which had previously been used to analyse the fragmentation behaviour of ballistically-loaded ceramic [21]. 
The calculation of normalised cumulative fragment mass for each of the samples is shown in Fig. 3. Each plotted data point shows the mean of the results for each fragment size with the error bars indicating the spread of the data.

Fig. 3: NEAR HERE

For the Sintox ${ }^{\mathrm{TM}} \mathrm{FA}$ and the Ekasic ${ }^{\circledR T}$ samples, the degree of fragmentation was found to be similar. Whereas, for the PS-5000 sample, much more extensive comminution had occurred due to its lower fracture toughness [25].

Further analysis using a JEOL 840A Scanning Electron Microscope on some of the smaller discrete fragments revealed that a certain amount of particulation had occurred down to ca. 50-500 $\mu \mathrm{m}$ (see Fig. 4). As expected, the ceramic fracture surfaces were undulated as a consequence of the intergranular and transgranular nature of the failure.

Fig. 4: NEAR HERE

For the samples retained for ballistic testing, each tile was placed within a cardboard structure and a thin layer of epoxy resin was applied to the surface to prevent any fragments from becoming detached. It was assumed that this thin layer would have no effect on the resistance to penetration due to the small volume that was used as well as its low strength and density.

Impact testing 
The range set up was one of a fixed test barrel mounted ten metres from the target. Bullet velocity was measured using a light-screen arrangement. The test ammunition was $7.62 \mathrm{~mm} \times 51 \mathrm{~mm}$ NATO FFV ammunition that generated a mean bullet velocity of $935 \mathrm{~m} / \mathrm{s}$. This bullet consists of a tungsten carbide core (composition by percentage weight C 5.2, W 82.6, Co 10.5, Fe 0.41) [26] of hardness 1550 [HV0.3], mounted in a low carbon steel jacket with gilding metal, on an aluminium cup. The measured hardness values of the steel jacket were 184 [HV0.3] at the base and 220 [HV0.3] at the tip. The masses of the core and the bullet were $5.90 \mathrm{~g}$ and $8.23 \mathrm{~g}$ respectively. Key dimensions of the core are shown below in Fig. 5.

Fig. 5: NEAR HERE

All ballistic tests we carried out using the heavy radial confinement rig (shown in Fig. 2). This was used to reduce the possibility of any release waves emanating from the edges of the tile during the penetration process. In addition, some of the targets were tested with an axial confinement of $6.0 \mathrm{~mm}$ of $\mathrm{Al} 6082-$ T651 (cover) plate held in position by a 10-mm thick steel retaining plate (see Fig. 1 (c)).

Both explosively shattered and intact materials were tested. After ballistic testing the aluminium alloy blocks were either sectioned or X-rayed to establish the residual penetration and to confirm the state of the projectile's core.

\section{RESULTS AND DISCUSSION}


Penetration into the intact tiles

All materials were tested intact (with no explosive loading) to allow comparison to the penetration with the tiles that had been explosively shattered. For both silicon carbide grades and the 20.0-mm thick Sintox ${ }^{\mathrm{TM}} \mathrm{FA}$ (with and without front confinement), the core was destroyed by the ceramic and consequently there was zero penetration into the witness plates. The $6.5-\mathrm{mm}$ thick and $12.0 \mathrm{~mm}$ thick Sintox ${ }^{\mathrm{TM}}$ FA targets both resulted in penetration with the core heavily damaged for the thicker of the two samples. With the $6.5 \mathrm{~mm}$ tile, the core was blunted and fractured and sustained less damage than occurred with the $12.0 \mathrm{~mm}$ tile. The experimental results are tabulated in Table 2. 
Table 2: NEAR HERE

It should be pointed out that our results for penetration into $6.5 \mathrm{~mm}$ of Sintox ${ }^{\mathrm{TM}} \mathrm{FA}$ backed by Al 6082-T6 also compared favourably to the depth of penetration recorded by Sapre [27] where the tile size was $100 \mathrm{~mm} \times 100 \mathrm{~mm}$ in area. This good agreement gives weight to the validity of the technique employed here, suggesting that the ballistic response of the relatively small $(50 \mathrm{~mm} \times 50 \mathrm{~mm})$ tiles held in a heavy steel containment rig is largely un-influenced by the target size.

Penetration of the pre-damaged ceramic targets

The results from the penetration experiments into the ceramic-faced targets are shown in Fig. 6. Where a cover-plate was introduced, this thickness was added to the behind-ceramic penetration depth to record the total penetration into the aluminium alloy.

The first thing to note is that there was a linear drop off in penetration as the thickness of the Sintox ${ }^{\mathrm{TM}} \mathrm{FA}$ tile was increased, indicating that the target material offered a similar level of resistance irrespective of the tile thickness. Secondly, it can be seen from Fig. 6 that the shattered silicon carbide results sit on or close to the linear trend line calculated for the Sintox ${ }^{\mathrm{TM}} \mathrm{FA}$ data. This shows that both the shattered silicon carbide targets performed similarly to the alumina targets despite the fact that they are twice as strong (see Table 1). On the other hand, when the intact tile is subjected to similar penetration experiments (again where the core remains intact), it has been shown that the silicon carbide targets considerably out 
perform the relatively soft alumina [22]. Consequently, Fig. 6 suggests that it is not the initial strength of the intact material that governs the resistance to these preshattered materials. Rather, it is the shape and structure of the interlocking fragments and importantly, how the interlocking fragments are able to slide passed one another during penetration that dominates behaviour. This observation is consistent with the work by Curran et al. [28]. They presented a micromechanical model that showed that for the case of penetration of long rods into thick ceramic plates, the confinement pressure and the inter-particle friction in the comminuted material are the key factors governing the penetration depth. However, it is worth noting that their model was applied to intact thick ceramic materials as opposed to the pre-fractured thin materials discussed here. Nevertheless, it appears that it is the fragment morphology and in particular, how they flow passed one another that are important in providing a resistance to penetration in this setup.

Notice too, the similarity in behaviour of the two silicon carbides despite the differences in the degree of fragmentation (see Fig. 3). Both of these silicon carbides possess similar hardness values and, when intact, behave in a similar fashion. This implies that in this experimental setup, the extent of fragmentation of the tile is not important in terms of offering resistance to penetration. Similar results have been shown by Lou and Wen [29] using a modified Split-Hopkinson-PressureBar Apparatus. They employed a novel dynamic compressive technique to load a ceramic sample with two consecutive stress pulses. This technique enabled the ceramic to be damaged to a desired level whilst retaining structure and then interrogated with regards to its dynamic behaviour. They showed that beyond a 
critical level of damage, the specimen behaved as if it flowed plastically and importantly, was insensitive to further levels of damage.

Fig. 6: NEAR HERE

There is one final point to note from Fig. 6. There is very little statistical difference between the tiles with the cover plates and those without. Increased levels of confinement should lead to an improvement in the ballistic performance of most brittle targets. However, this effect is most noticeable with impacts involving rods (e.g., [15]) where the thicknesses of the ceramic, and consequently the timescales of projectile / target interaction are much larger. For all the brittle materials tested in this work, little-to-no advantage was offered by adding a front cover confinement when the thickness of the plate was taken into account. Given that the cover-plate used in this work was ca. 6-mm thick (and in all cases $>10 \%$ of the behind-ceramic penetration) it is probable that the advantage of providing front cover confinement is outweighed by the additional aluminium that is penetrated before penetration of the ceramic ensued (and consequently added to the DoP values). Given that comparable behaviour was noted for the intact tiles in that the penetration depths were similar, this seems a reasonable conclusion. Finally, if the 6-mm thickness is deducted from the results where a cover plate was used there is evidence of a small reduction in penetration into the aluminium witness plate. However, it should be noted that this is not representative of the total material penetrated. Furthermore, the thickness of the cover plate is frequently taken into account in performance metrics e.g., [15] and therefore it is appropriate to show that here. 
Ballistic performance of the shattered materials

Finally, the ballistic performance, taking into account the thickness and the density of the respective ceramics can be calculated using [15]:

$$
E_{m}=\frac{\rho_{a l} p_{\infty}}{\rho_{c} t_{c}+\rho_{a l} p_{r}+\rho_{a l} T_{c p}}
$$

where $\rho$ refers to the density of the material and the subscripts ' $c$ ' and ' $a$ ' refer to the ceramic and aluminium respectively; $T_{c p}$ is the thickness of the cover plate (if there was one).

Essentially, this metric $\left(E_{m}\right)$ compares the ballistic performance of the ceramic-faced target to the ballistic performance of the aluminium alloy plate alone. A value greater than 1.0 indicates that the ceramic-faced target is performing better than the aluminium without a ceramic face (on a weight-by-weight basis). Penetration into the witness plate alone (without a ceramic in place - see Fig. 1(a)) yielded a nominal value of $\mathrm{p}_{\infty}=70 \mathrm{~mm}$ and was adjusted according to the impact velocity ( $\pm 2 \mathrm{~mm}$ ) from penetration - velocity measurements. A plot of this data for both the intact Sintox ${ }^{\mathrm{TM}} F A$ and the shattered ceramics tested in this work is provided in Fig. 7. Unfortunately, no intact silicon carbide samples provided a depth of penetration over the thickness of interest and consequently these have been omitted here. Equally the 20-mm thick Sintox ${ }^{\mathrm{TM}}$ FA yielded no residual penetration 
and have consequently been omitted. Extra data for the Sintox ${ }^{\mathrm{TM} F A}$ is provided by Sapre [27].

Figure 7: NEAR HERE

A few observations can be drawn from Fig. 7. The shattered ceramic tiles demonstrate a relatively weak correlation between the mass efficiency and the tile thickness although we should be cautious about drawing firm conclusions on this given the minimal statistical difference between the sets of data. More telling is the fact that the mass efficiency of the silicon carbides and the Sintox ${ }^{\mathrm{TM}} \mathrm{FA}$ appear similar. This implies a similar level of resistance between these different types of materials irrespective of their strength values as we discussed earlier.

Turning our attention to the intact data it appears that there is a strong correlation between efficiency and thickness; positive correlation has also been seen by other researchers with different projectiles and ceramic materials [30]. Finally, the difference between the ballistic performance of the pre-damaged tiles to intact tiles increases dramatically as the tile thickness is increased. This was due to the extensive damage done to the core by the thicker intact Sintox ${ }^{\mathrm{TM}} \mathrm{FA}$ tiles, consequently resulting in an increase in the $E_{m}$ value for this thickness.

\section{CONCLUSIONS}

Explosively-loaded ceramic tiles of different strengths have been subjected to depth-of-penetration experiments and the results have shown that there is little 
difference in the DoP or the mass efficiency of these damaged materials. This was taken as evidence that the important controlling parameter for enhancing the ballistic performance of a damaged ceramic material was not the strength of the ceramic but rather the fragment morphology. Consequently, the resistance to penetration offered by a damaged ceramic is most-likely dominated by the interparticular friction and flow characteristics of the comminuted material. Furthermore, there was little change in performance between the two silicon carbides despite differing levels of measured fragmentation. Finally, when compared to the intact tiles, very little difference between the intact tiles and the shattered tiles was shown at low thicknesses; however as the tile thickness was increased, the difference increased due to heavy damage to the bullet core.

\section{ACKNOWLEDGEMENTS}

The authors particularly wish to thank Morgan AM \& T and ESK for providing free samples for this study. In particular they would like to thank $\mathrm{Mr}$ Eddie Belfield (ESK) and Mr Colin Roberson (Advance Defence Materials Ltd) for their helpful support in this matter. They would also like to acknowledge Mr David Miller for conducting the firings and Mr Andrew Roberts for this technical support. The majority of this work was carried out during the project phase of an Explosive Ordnance Engineering MSc course at Cranfield University (Shrivenham). 


\section{REFERENCES}

1. T. J. Holmquist, G. R. Johnson: 'Response of silicon carbide to high velocity impact', J. of Appl. Phys., 2002, 91, 5858-5866.

2. G. R. Johnson and T. J. Holmquist: 'Some observations on the strength of failed ceramic’. In: J.J. Swab, D. Zhu, W.M. Kriven, (Eds)., Ceramic Engineering and Science Proceedings, 2006, 26, (7), 3-10.

3. J. Lankford Jr: 'The Role of Dynamic Material Properties in the Performance of Ceramic Armor', Int. J. Appl. Ceram. Technol., 2004, 1 (3), 205-210.

4. C. E. Anderson Jr., T. Behner, D. L. Orphal, A. E. Nicholls, D. W. Templeton: 'Time-resolved penetration into pre-damaged hot-pressed silicon carbide’. Int. J. Impact Engng, 2008, 35 (8), 661-673.

5. S. Chocron, K. A. Dannemann, A. E. Nicholls, J. D. Walker, C. E. Anderson Jr., 'A constitutive model for damaged and powder silicon carbide’. In: J.J. Swab, D. Zhu, W.M. Kriven, (Eds.), Ceramic Engineering and Science Proceedings, 2005, 26 (7), 35-42.

6. I. Horsfall, M. R. Edwards, M. J. Hallas: 'The ballistic and physical properties of highly fractured alumina', Advances in Applied Ceramics, 2010, 109 (8), 498-503.

7. K. A. Dannemann, A. E. Nicholls, S. Chocran, J. D. Walker: 'Compression testing and response of SiC-N ceramics: intact, damaged and powder', In: J.J. Swab, D. Zhu, W.M. Kriven, (Eds.), Ceramic Engineering and Science Proceedings, 2005, 26 (7), 109-116.

8. Walley SM: 'Historical review of high strain rate and shock properties of ceramics relevant to their application in armour'. Advances in Applied Ceramics, 2010, 109 (8), 446-466.

9. R. L. Woodward, B. J. Baxter: 'Ballistic evaluation of ceramics: Influence of test conditions', Int. J. of Impact Engng., 1994, 15, 119-124 
10. C. Roberson, P. J. Hazell: 'Resistance of silicon carbide to penetration by a tungsten carbide cored projectile’. In: E. Medvedovski (Ed.,) Ceramic Armor and Armor Systems, Ceramic Transactions, 2003, 151, 165-174.

11. R. Klement, S. Rolc, R. Mikulikova, J. Krestan, ‘Transparent armour materials', Journal of the European Ceramic Society, 2008, 28 (5), 10911095.

12. P. J. Hazell, C. Roberson and M Moutinho, 'The design of mosaic armour: the influence of tile-size on the ballistic performance', Materials and Design, 2008, 29 (8), 1497-1503.

13. P. J. Hazell, N. A. Fellows and J. G. Hetherington, 'A note on the behind armour effects from perforated alumina/aluminium targets', Int. J. of Impact Engng., 1998, 21, 589-595.

14. D. Ray, R. Flinders, A. Anderson and R. Cutler, 'Effect of roomtemperature hardness and toughness on the ballistic performance of SiCbased ceramics'. In: J.J. Swab, D. Zhu, W.M. Kriven, (Eds.), Ceramic Engineering and Science Proceedings, 2005, 26 (7), 131-142.

15. C. E. Anderson Jr and S. A. Royal-Timmons, 'Ballistic performance of confined 99.5\%-Al203 ceramic tiles', Int. J. Impact Engng., 1997, 19, 703713.

16. R. R. Franzen, D. L. Orphal DL and C. E. Anderson Jr, ‘The influence of experimental design on depth-of-penetration (DOP) test results and derived ballistic efficiencies’. Int. J. Impact Engng., 1997, 19 (8), 727-737.

17. B. James, 'The influence of material properties of alumina on ballistic performance'. In the proceedings of the 15th International Symposium on Ballistics, 21-24 May 1995, Jerusalem, Israel, pp. 3-9; ISBN 0-961-8156-04.

18. V. Hohler, K. Weber, R. Tham, B. James, A. Barker and I. Pickup, 'Comparative analysis of oblique impact on ceramic composite systems', Int. J. of Impact Engng., 2001, 26, 333-344.

19. Z. Rosenberg, Y. Yeshurun, S. J. Bless and K. Okajima, 'A new definition of ballistic efficiency of brittle materials based on the use of thick backing plates', in 'Impact loading and dynamic behaviour of materials', (ed. C. Y. 
Chiem et al.), 491-498; 1988, Oberursel, DGM Informationsgesellschaft $\mathrm{mbH}$.

20. Z. Rosenberg and Y. Yeshurun, 'The relation between ballistic efficiency and compressive strength of ceramic tiles'. Int. J. Impact Engng., 1988, 7 (3), 357-362.

21. R. L. Woodward, W. A. Gooch Jr., R. G. O'Donnell, W. J. Perciballi, B. J. Baxter and S. D. Pattie, 'A study of fragmentation in the ballistic impact of ceramics’. Int. J. Impact Engng., 1994, 15 (5), 605-618.

22. P. J. Hazell, 'Measuring the strength of brittle materials by depth-ofpenetration testing'. Advances in Applied Ceramics, 2010, 109, (8), 504-510.

23. J. R. Hearst and C. S. Lynch, 'Measurement of in situ strength using projectile penetration', Int. J. Rock Mech. Min. Sci. \& Geomech. Abstr. 1994, 31, No. 3,243-251.

24. www.matweb.com, last accessed 10 August 2010

25. S. Kaur, R. A. Cutler and D. K. Shetty, 'Short-crack fracture toughness of silicon carbide’, J. Am. Ceram. Soc., 2009, 92 (1), 179-185.

26. M. R. Edwards and A. Mathewson, 'The ballistic properties of tool steel as a potential improvised armour plate’. Int. J. Impact Engng., 1997, 19 (4), 297309.

27. S. Sapre, "Measuring the material resisting force during projectile penetration”, Explosives Ordnance Engineering (EOE) MSc thesis, Cranfield Defence and Security, Cranfield University, Shrivenham, UK, July 2009.

28. D. R. Curran, L. Seaman, T. Cooper and D. A. Shockey, 'Micromechanical model for comminution and granular flow of brittle material under high strain rate application to penetration of ceramic targets', Int. J. of Impact Engng., 1993, 13, (1),53-83.

29. H. Luo and W. Chen, 'Damage effects on the dynamic response of hotpressed SiC-N’. In: J.J. Swab, D. Zhu, W.M. Kriven, (Eds.), Ceramic Engineering and Science Proceedings, 2005, 26 (7), 117-122. 
30. V. Madhua, K. Ramanjaneyulu, T. Balakrishna Bhat, N. K. Gupta, ‘An experimental study of penetration resistance of ceramic armour subjected to projectile impact’, Int. J. of Impact Engng., 2005, 32, 337-350. 
TABLES

TABLE 1

\begin{tabular}{|l|c|c|c|c|c|c|c|}
\hline Material & $\begin{array}{c}\rho_{0} \\
(\mathrm{~g} / \mathrm{cc})\end{array}$ & $\begin{array}{c}\mathrm{C}_{\mathrm{l}} \\
(\mathrm{mm} / \mu \mathrm{s})\end{array}$ & $\begin{array}{c}\mathrm{C}_{\mathrm{s}} \\
(\mathrm{mm} / \mu \mathrm{s})\end{array}$ & $\begin{array}{c}E \\
(\mathrm{GPa})\end{array}$ & $v$ & $\begin{array}{c}\text { Yield } \\
\text { Strength } \\
(\mathrm{MPa})\end{array}$ & $\begin{array}{c}\text { Hardness } \\
(\mathrm{GPa})\end{array}$ \\
\hline $\mathrm{Al} \mathrm{6082-T651}$ & 2.70 & 6.41 & 3.19 & 73 & 0.34 & $240[24]$ & 1.1 \\
\hline $\begin{array}{l}\text { Sintox } \\
\left(\mathrm{Al}_{2} \mathrm{O}_{3}\right)\end{array}$ & 3.73 & 10.09 & 5.93 & 321 & 0.24 & - & 11.0 \\
\hline Ekasic ${ }^{\mathrm{TM}} \mathrm{T}(\mathrm{SiC})$ & 3.21 & 12.21 & 7.66 & 443 & 0.18 & - & 21.4 \\
\hline PS-5000 (SiC) & 3.15 & 12.07 & 7.63 & 427 & 0.16 & - & 24.3 \\
\hline
\end{tabular}

TABLE 2

\begin{tabular}{|c|c|c|c|}
\hline $\begin{array}{c}\text { Target } \\
\text { material }\end{array}$ & $t_{c}(\mathrm{~mm})$ & Cover plate? & $p_{r}(\mathrm{~mm})$ \\
\hline PS-5000 & $9.0 \pm 0.06$ & No & 0 \\
\hline & $9.0 \pm 0.06$ & Yes & 0 \\
\hline Ekasic ${ }^{R} \mathrm{~T}$ & $10.2 \pm 0.06$ & No & 0 \\
\hline & $10.2 \pm 0.06$ & Yes & 0 \\
\hline Sintox ${ }^{\mathrm{TM}} \mathrm{FA}$ & $6.5 \pm 0.10$ & No & $31.0 \pm 1.0$ \\
\hline & $12.0 \pm 0.05$ & No & $11.0 \pm 2.0$ \\
\hline & $20.0 \pm 0.10$ & No & 0 \\
\hline & $6.5 \pm 0.10$ & Yes & $27.4 \pm 2.4$ \\
\hline & $12.0 \pm 0.05$ & Yes & $7.9^{*}$ \\
\hline & $20.0 \pm 0.10$ & Yes & 0 \\
\hline
\end{tabular}

*only one test was carried out for this thickness and confinement condition. 


\section{LIST OF CAPTIONS}

Fig. 1: DoP technique for assessing each sample’s ballistic performance; (a) without target sample in place; (b) with target sample in place (radially confined) and; (c) with front and radial confinement.

Fig. 2: Experimental set-up for the explosive loading of the tile, shown here restrained insitu within the confinement rig.

Fig. 3: Normalised cumulative mass calculation of fragments for Sintox ${ }^{\mathrm{TM}} \mathrm{FA}$ and the two silicon carbides (PS-5000 and Ekasic ${ }^{\mathrm{T}}$ ).

Fig. 4: Scanning electron micrographs of explosively shattered alumina.

Fig. 5: Key dimensions of the WC-Co FFV core; all dimensions are in mm.

Fig. 6: Penetration results for the pre-shattered ceramic-faced targets; where the cover-plate was introduced, its thickness was added to the depth-of-penetration measurement.

Figure 7: Calculated mass effectiveness of the shattered ceramic samples and the intact Sintox ${ }^{\mathrm{TM}} \mathrm{FA}$ samples.

Table 1: Properties of the materials tested (in order of hardness).

Table 2: Experimental results from the tested intact tiles. 
Fig. 1
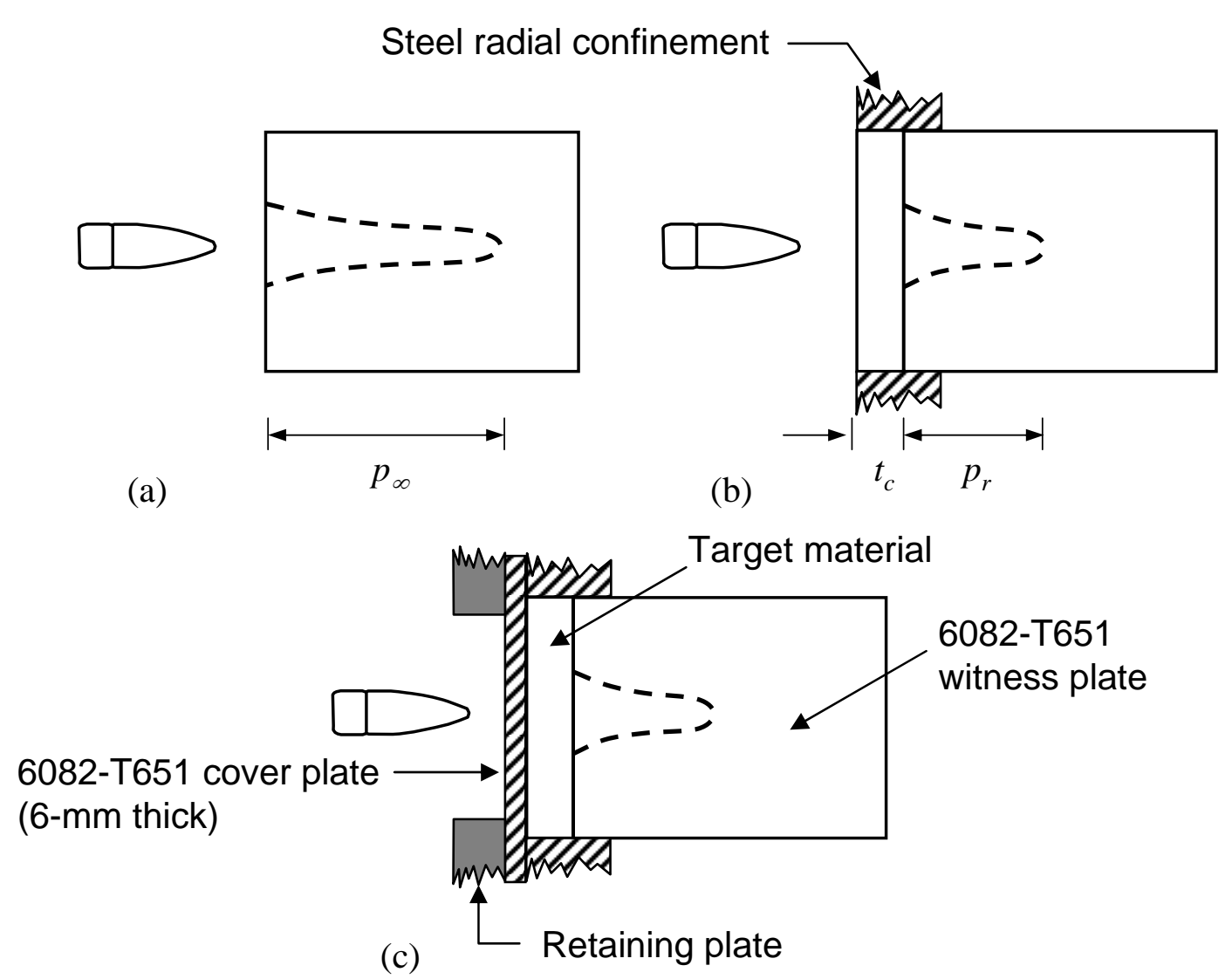


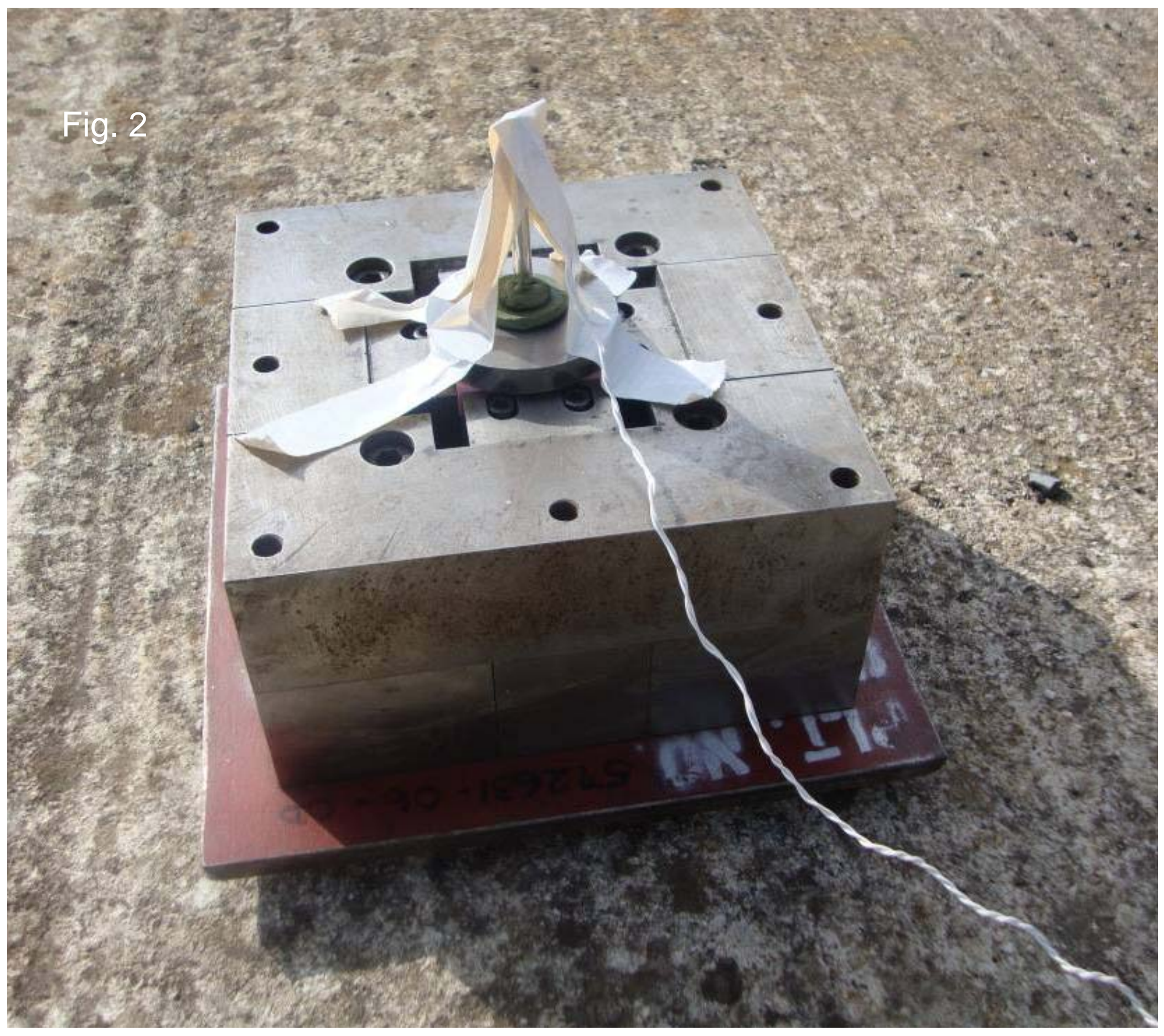


Fig. 3

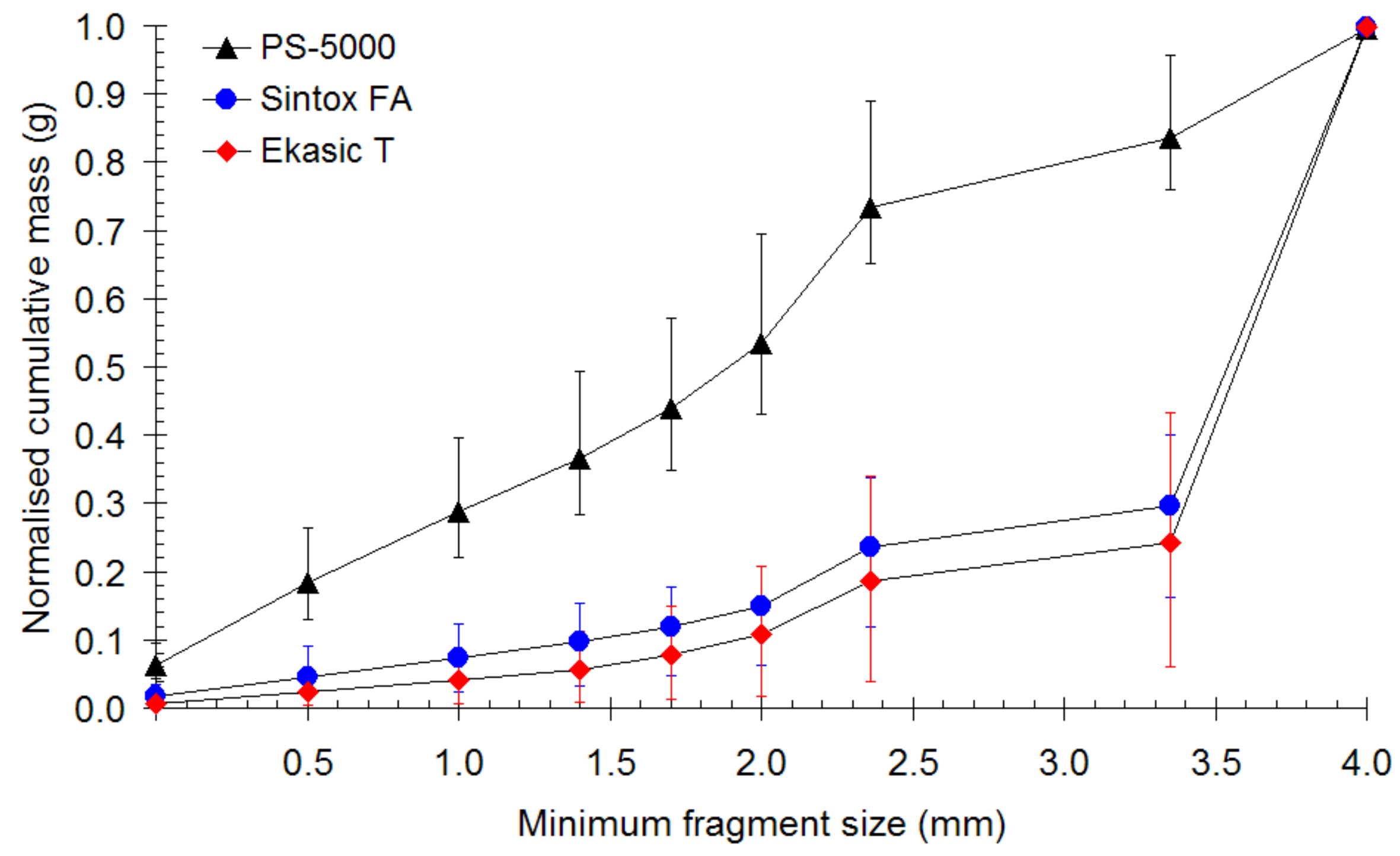




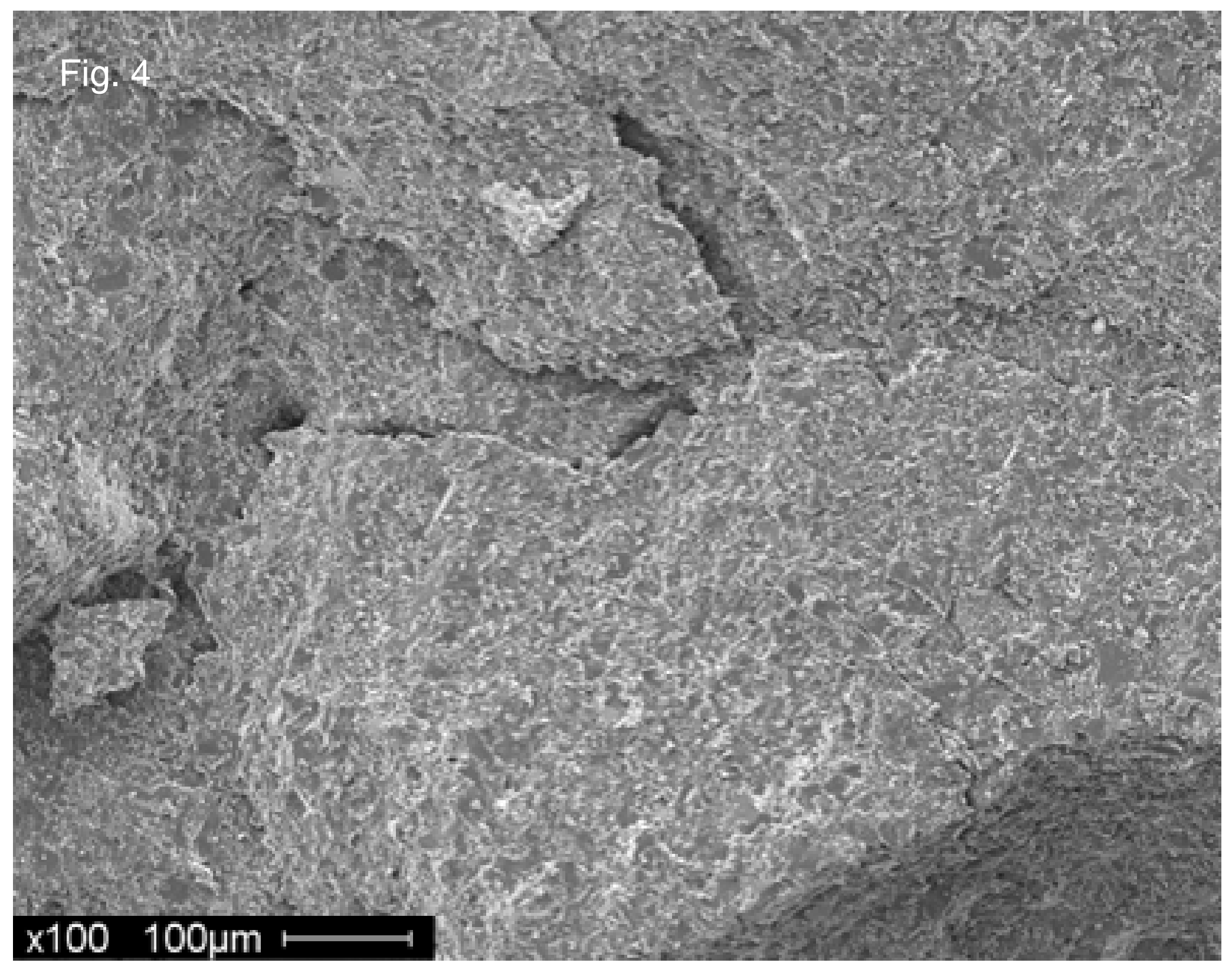


Fig. 5

20.10

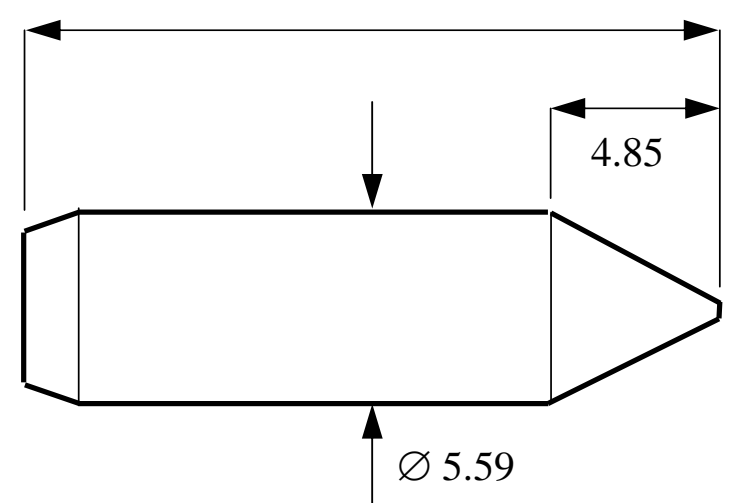


Fig. 6

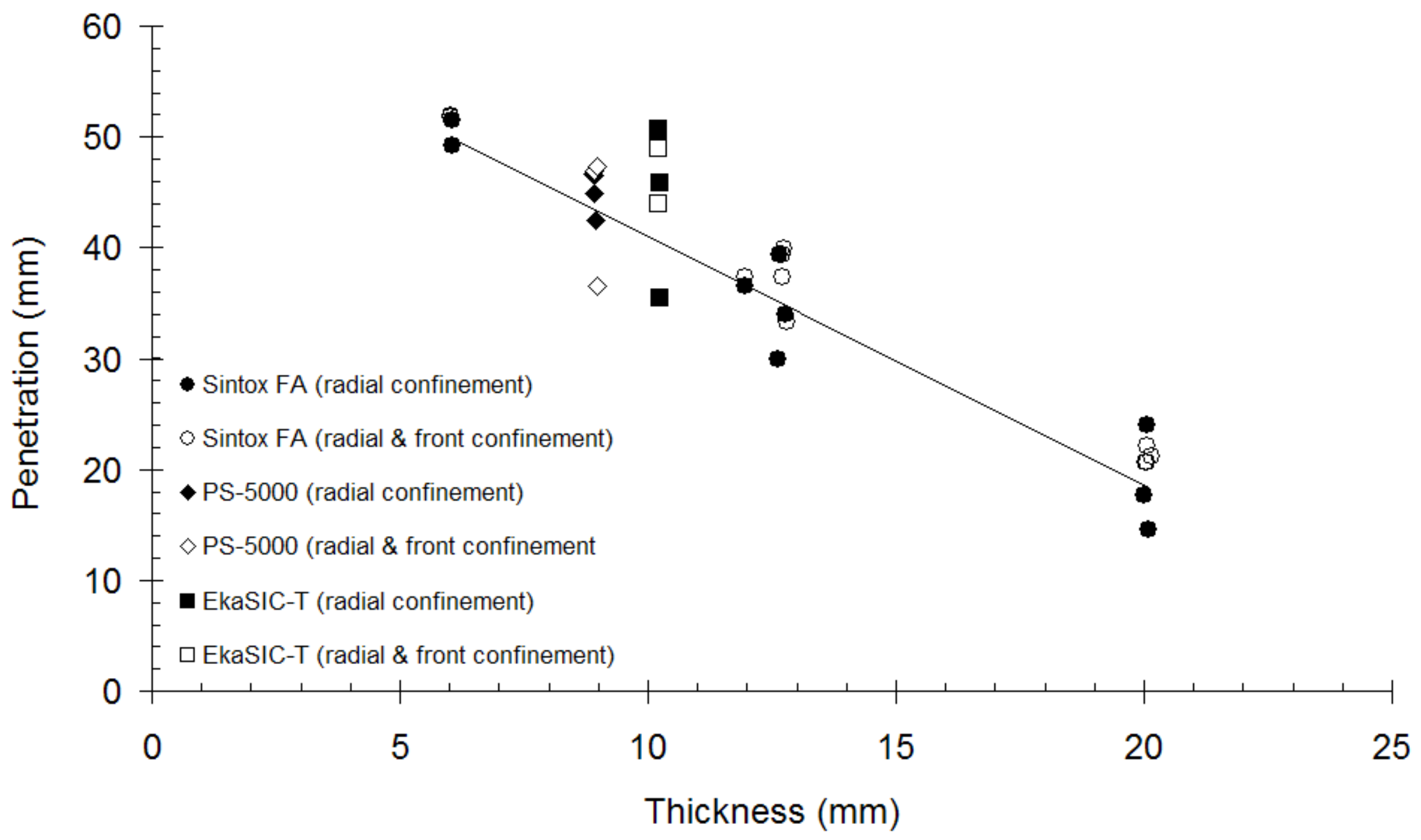


Fig. 7

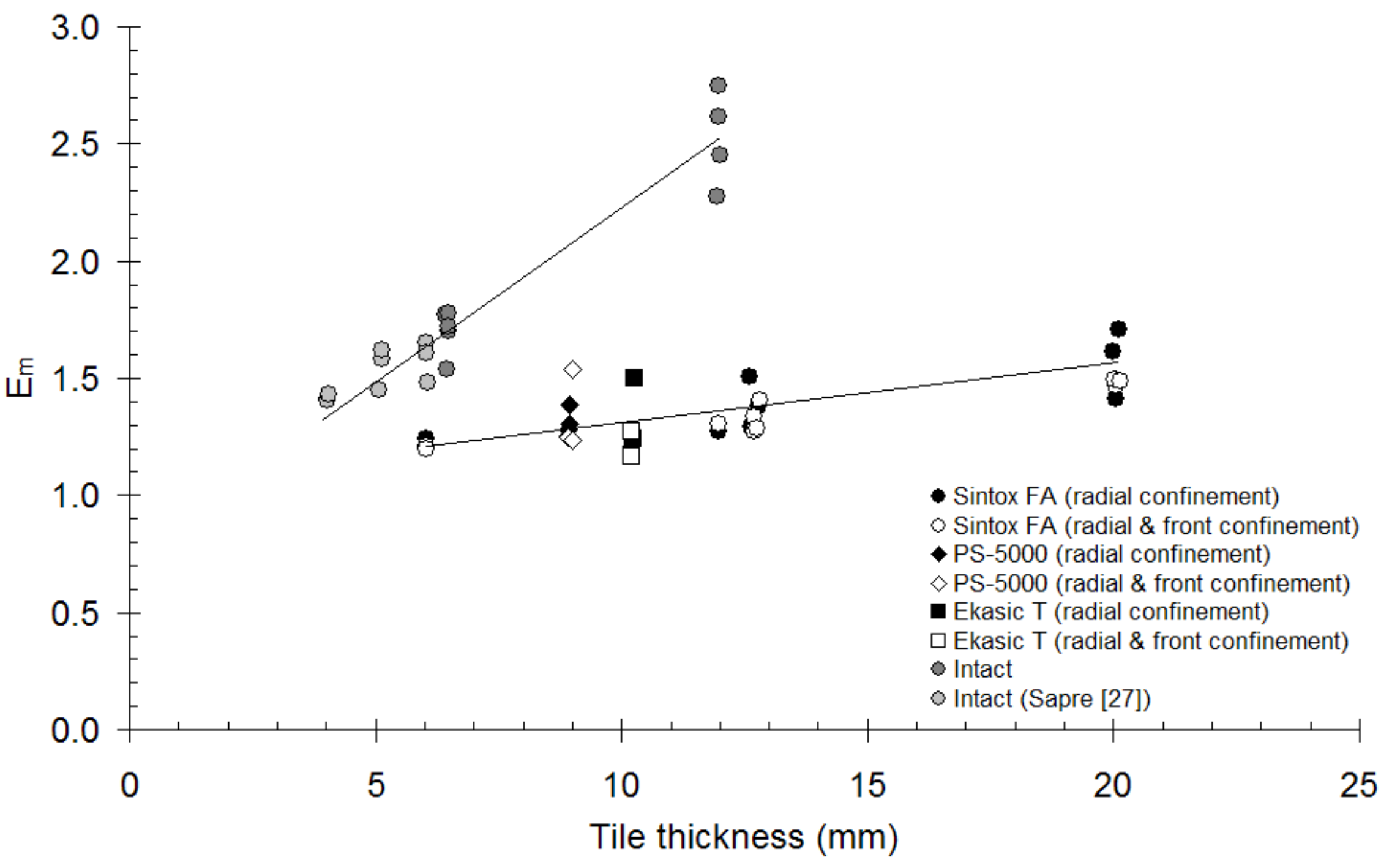

